\title{
ПРИМЕНЕНИЕ РУКОВОДСТВА ОЭСР ПО ТРАНСФЕРТНОМУ ЦЕНООБРАЗОВАНИЮ В РОССИИ
}

\begin{abstract}
Аннотация. В настоящее время в связи с вступлением в силу с 1 января 2012 г. измененных правил налогового контроля трансфертного ценообразования в России начинает складывается практика их применения и возникают вопросы их толкования. Поскольку российские правила налогового контроля трансфертного ценообразования основаны на рекомендациях Руководства ОЭСР по трансфертному ценообразованию для транснациональных корпораций и налоговых органов, возникает вопрос о возможности их применения налогоплательщиками и налоговыми органами в России. Автор анализирует складывающуюся судебную и административную практику по данномувопросу и формирует самостоятельный подход к данной проблеме. Автор приходит к выводу, что Руководство ОЭСР может применяться как продолжающее, конкретизирующее, развивающее и восполняющее пробелы в российском регулировании относительно применения методов трансфертного ценообразования в случае совпадения логики и целей налогового контроля трансфертного ценообразования, содержащихся в Руководстве ОЭСР и Налоговом кодексе Российской Федерации.
\end{abstract}

Ключевые слова: трансфертное ценообразование, принцип “вытянутой руки”, налоговый контроль, распределение затрат, Руководство ОЭСР, тестируемая сторона, "портфельный” подход, взаимозависимые лица, группа компаний, ФНС России.

Review. As a result of amended rules for tax control of transfer pricing in Russia as of January 1, 2012, currently these rules are being implemented which creates questions about how to interpret them. The fact that Russian rules for tax control of transfer pricing are based on the recommendations set forth in the OECD Transfer Pricing Guidelines for transnational corporations and tax authorities raises a question about whether these rules can be applied by taxpayers and tax authorities in Russia. The author of the article analyses the current judicial and administrative practice on the matter and develops her own approach to the problem. In her research Zadorozhnaya concludes that the OECD Guidelines can be applied as the source that continues, clarifies, develops and fills in the gaps in the Russian regulation of the methods of transfer pricing in case the logic and targets of tax control over transfer pricing are the same in the OECD Guidelines and Tax Code of the Russian Federation.

Keywords: transfer pricing, arm's length principle, tax control, distribution of costs, OECD Guidelines, tested party, portfolio balance approach, related parties, group of companies, Federal Tax Service of Russia.

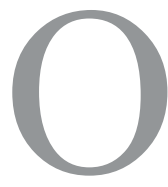
рганизация экономического сотрудничества и развития (далее - ОЭСР) - международная структура, созданная с целью обмена передовым опытом экономической и социальной политики [1]. В 1995 г. ОЭСР выпустила «Руководство по трансфертному ценообразованию для транснациональных корпораций и налоговых органов» [2] (далее - Руководство), являющееся «основным рекомендательно-методическим документом в области налогового регулирования трансфертного ценообразования, положения которого в той или иной степени учитываются в законодательстве и правоприменительной деятельности различных стран мира, в том числе тех, которые не являются участниками ОЭСР» [3].

В 2010 г. были внесены изменения в разделы I-III Руководства, добавлен раздел IX, а 5 октября 2015 г. ОЭСР опубликовала документы, разработанные в рамках Программы по противодействию размыванию налоговой базы и ухода от налогообложения [4], которые также предполагают внесение изменений в Руководство.

Российские правила налогового контроля трансфертного ценообразования основаны на Руководстве [5]. Судебная практика, складываю- 


\section{Налоги и налогообложение 8(146) • 2016}

щаяся в России на данный момент, принимает во внимание Руководство при разрешении вопросов трансфертного ценообразования, использует его как дополнительный аргумент в сторону одной из позиций.

Разрешая спор в деле ЗАО «Королевский Банк Шотландии» [6], суд обоснованно принял во внимание положения рекомендаций ОЭСР по трансфертному ценообразованию, которая объединяет 30 стран-участников и сотрудничает более чем с 70 странами, включая Российскую Федерацию, и Модельной налоговой конвенции ОЭСР, поскольку в рассматриваемой ситуации имеет место налогообложение прибыли, полученной при реализации прав и обязанностей по международным соглашениям, в которых использован ряд терминов и понятий (в том числе определяющих принципы распределения прибыли и бремени расходов между их участниками - принцип «вытянутой руки»), закрепленных именно в названных рекомендациях и конвенции.

Так, в деле 000 «Объединение “Пивоварни Хейнекен”» [7] суд указал, что в соответствии с представленным в материалы дела Письмом Министерства экономического развития РФ от 17.09.2009 №Д 13-1621 установленный агентским договором способ распределения вознаграждения агента между несколькими принципалами соответствует международной практике, в частности рекомендациям Организации экономического сотрудничества и развития (ОЭСР) по трансфертному ценообразованию.

По делу 000 «Эквант» [8] суд руководствовался следующим. Руководство предписывает при анализе трансфертного ценообразования по внутригрупповым услугам установить, во-первых, были ли оказаны данные услуги, а во-вторых, соответствуют ли отношения по оказанию этих услуг принципу «вытянутой руки», т.е. могут ли они иметь место между независимыми лицами, не связанными волей контролирующей компании. С этой точки зрения спорные расходы по лицензионному соглашению также не могут быть привлечены для целей налогообложения, так как в силу отсутствия объекта лицензионного соглашения их нельзя считать реальными, а независимый субъект по той же причине подобное соглашение не заключил бы.
Министерство финансов Российской Федерации (далее - Минфин России) указывает, что возможно использование положений Руководства в отношении трансграничных сделок (т.е. сделок, в результате совершения которых возникают налоговые последствия в нескольких юрисдикциях), но исключительно при условии, если это не противоречит положениям законодательства Российской Федерации о налогах и сборах [9].

На данном этапе рассуждений возникает вопрос, в каких ситуациях данное противоречие возникает? Рассмотрим пример, когда в своем письме Минфин России учел «общепринятый в международной практике подход» кприменению правил налогового контроля трансфертного ценообразования, содержащийся в Руководстве [10]. Минфин России указал, что при определении сопоставимости предмет сделки имеет второстепенное значение. Основными факторами, влияющими на ценообразование, являются вид осуществляемой лицом деятельности и связанные с ним функции (В соответствии с подп. 1.41 п. D.1.2.1 раздела I Руководства на практике было установлено, что в рамках анализа сопоставимости для методов, основанных на индикаторах валовой или чистой прибыли, функциональной сопоставимости часто уделяется большее внимание, чем сопоставимости характеристик товаров.). Налоговый кодекс Российской Федерации [11] (далее - НК РФ) в этом случае лишь перечисляет критерии сопоставимости и, таким образом, равнозначно оценивает и предмет, и функции сторон в рамках сделки (п. 4 ст. 105.5 НК РФ).

Приведем несколько других примеров, когда применение рекомендации Руководства, не предусмотренной НК РФ, могло бы оказаться обоснованным. Необходимо отметить, что все они касаются применения методов трансфертного ценообразования для расчета рыночного уровня цен (рентабельности).

\section{1. Выбор «тестируемой» стороны}

По правилам п. 6 ст. 105.12 НК РФ, с рыночным интервалом рентабельности сопоставляется рентабельность той стороны анализируемой сделки, которая отвечает следующим требованиям:

1) сторона анализируемой сделки осуществляет функции, вклад которых в полученную прибыль по сделкам, последовательно совершен- 


\section{Тема: Проблемы налогообложения в условиях трансфертного ценообразования}

ным с одним и тем же товаром, меньше, чем вклад другой стороны анализируемой сделки;

2) сторона анализируемой сделки принимает меньшие экономические (коммерческие) риски, чем другая сторона анализируемой сделки;

3) сторона анализируемой сделки не владеет объектами нематериальных активов, оказывающими существенное влияние на уровень рентабельности.

По п. 7 ст. 105.12 НК РФ, в случае, если сторона анализируемой сделки не отвечает требованиям, предусмотренным подп. 1-3 п. 6 ст. 105.12 НК РФ, для сопоставления с рыночным интервалом рентабельности выбирается та сторона анализируемой сделки, которая в наибольшей степени отвечает указанным требованиям.

Данное правило основано на экономических принципах: чем сторона «проще» (т.е. чем меньше функций, рисков и активов она на себя берет), тем меньше факторов влияют на ее рентабельность по сделке и тем скорее эта рентабельность является «чистым» показателем, отражающим прибыльность именно от анализируемой сделки (например, от передачи товаров (выполнения работ, оказания услуг). Чем больше активов, рисков и функций берет на себя сторона, тем большую долю прибыли она вправе получить. Тестируя сторону, которая обладает значительными нематериальными активами, сложно будет определить, за счет чего установился тот или иной уровень рентабельности, какая часть прибыли «принадлежит» нематериальному активу, а какая - собственно анализируемой сделке.

Однако на практике складываются ситуации, когда рентабельность более «простой» стороны все же больше подвержена влияниям, чем рентабельность более «сложной» стороны. В частности, такие ситуации возникают в сделках по приобретению услуг (работ), а также в сделках по приобретению товаров для последующей перепродажи взаимозависимым лицам.

В первой ситуации компания, приобретающая услуги, является более «простой», так как услуги оказывает другая компания - исполнитель, и, соответственно, основные функции лежат на ней. Однако, если компания, занимающаяся производством товаров, приобретает консультационные услуги, вся ее рентабельность основана именно на деятельности от произ- водства и продажи товаров, и выделить из нее часть, относящуюся к сделке по приобретению консультационных услуг, не представляется возможным.

Во второй ситуации компания имеет возможность «компенсировать» свою заниженную/ завышенную рентабельность за счет цен в последующих сделках со своими взаимозависимыми лицами. Например, приобретая товары у одного взаимозависимого лица по заниженным ценам, перепродает их другому взаимозависимому лицу по завышенным ценам. Такими действиями не только выравнивается уровень рентабельности, но и усиливается эффект от низконалоговой юрисдикции.

В такой ситуации Руководство предлагает нам ориентироваться не столько на функциональный профиль компании, сколько на качество информации: тестируемой может быть избрана та сторона по сделке, анализ которой даст наиболее обоснованный результат (подп. 3.18. А 3.3. раздела III Руководства).

В рассматриваемых примерах, хотя НК РФ и не предполагает такой подход, более обоснованный результат может дать тестирование компании, (1) оказывающей консультационные услуги (для первой ситуации), (2) покупающей товар у взаимозависимого лица и перепродающей его независимым лицам (для второй ситуации), хотя бы даже такая компания имеет более сложный набор функций, рисков и активов в сделке. В противном случае имплементация и применение только одной части данной концепции без учета второй части может искажать результат ее применения как таковой.

2. Расчет рентабельности стороны сделки, выполняющей функции посредника

Расчет рентабельности по сделке для применения затратного метода, метода цены перепродажи и метода сопоставимой рентабельности производится на основании данных бухгалтерского (финансового) учета (п. 2 ст. 105.8 НК РФ) по формулам, установленным в п. 1 ст. 105.8 НК РФ. Данные формулы применяются ко всем видам сделок одинаково и подразумевают каких-либо исключений. Согласно п. 2.93, 7.36 Руководства при оказании услуг, когда исполнитель по сути выступает в качестве посредника, некоторые расходы могут учитываться в цене без надбавки. 


\section{Налоги и налогообложение 8(146) • 2016}

T.е. в таких сделках, при расчете рентабельности можно учитывать только те расходы, которые понесены посредником при выполнении только его посреднической деятельности, и, таким образом, рассчитать его действительную рентабельность в сделке. Учет полной суммы расходов посредника (в т.ч. «перевыставляемых» заказчику накладных расходов на привлечение третьих лиц), как на данный момент установлено в НК РФ, приводит к уменьшению его рентабельности в сделке, что некорректно отражает его финансовый результат и не соответствует его роли по сделке.

\section{3. «Портфельный» подход}

В соответствии с НК РФ финансовый результат должен рассчитываться по каждой анализируемой сделке по отдельности для оценки рыночности цен в ней. Руководство же в пп. 3.10 п. А 3.1 Раздела III позволяет использовать так называемый «портфельный подход», подразумевающий объединение сделок в группу для оценки рыночности цен в них, если они связаны друг с другом экономической логикой. Данный подход представляет собой бизнес-стратегию по объединению налогоплательщиком конкретных сделок в группы для получения оптимальной прибыльности скорее по всей совокупности сделок, нежели обязательно по каждому виду продукции, входящему в «портфель». Например, налогоплательщик может продавать некоторые товары с низкой прибылью или даже с убытком, поскольку данные товары создают спрос на другую продукцию и/или относящиеся к ним услуги этого же налогоплательщика, продажа/оказание которых приносит высокую прибыль (например, оборудование и связанные с ним товары для их послепродажного обслуживания, такие как автоматы по продаже кофе и кофейные капсулы, или принтеры и картриджи). «Портфельный» подход является примером бизнес-стратегии, учет которой может быть необходим при анализе сопоставимости и проверке надежности сопоставимых данных.

Рассмотрев выше четыре примера (включая пример, рассмотренный Минфином России), когда подход НК РФ отличается от подхода Руководства ОЭСР необходимо ответить на вопрос, вызвано ли такое отличие пробелами в законодательстве или с дискрецией законодателя?
В соответствии с п. 3 ст. 3 НК РФ налоги и сборы должны иметь экономическое основание и не могут быть произвольными. Вопрос об экономическом основании налога является дискуссионным. Например, С.В. Овсянников отмечает, что «объект налогообложения - это экономическое основание налога, отраженное в правовой форме» [12]. В.М. Зарипов считает, что экономическое основание налога - это «добавленная стоимость, прибыль, чистый доход, природная рента, выгода от использования социально обеспеченных трудовых ресурсов или иная экономическая выгода, полученная налогоплательщиком» [13].

По мнению И.А. Хавановой, принцип экономического основания является одним из элементов более объемного принципа экономической обоснованности налогов, одним из аспектов которого является «обязанность законодателя обеспечить экономическую логику не только в поэлементной конструкции налога, но и в построении всей системы налогов и сборов... Экономическая система, как и любая другая система, обладает внутренней целостностью, и это объективное единство закономерно связанных предметов и явлений, познанных экономической наукой, должно приниматься во внимание наукой правовой» [14], «финансовые правоотношения являются юридической формой выражения и закрепления финансовых отношений, которые сами, в свою очередь, являются формой определенных экономических отношений» [15].

Представляется, что правила налогового контроля трансфертного ценообразования в части применения методов трансфертного ценообразования не могут быть основаны ни на чем ином, кроме как на экономических закономерностях, оказывающих влияние на цену в сделках на рынке, поскольку именно они призваны рассчитать цену (рентабельность) на «расстоянии вытянутой руки». Поэтому логика и цель применения методов трансфертного ценообразования у НК РФ и Руководства общая. Так, зачастую НК РФ воспроизводит правила о сопоставимости условий сделок и функциональном анализе сторон сделок [16], а также устанавливает общий с Руководством механизм применения методов.

В связи с этим в части применения методов трансфертного ценообразования Руководство может применяться как продолжающее, конк- 
ретизирующее, развивающее, восполняющее пробелы в российском регулировании. Причем такое применение будет означать применение не столько Руководства, сколько обоснованного экономического подхода, подкрепленного опытом международной практики. То есть при таком подходе Руководство не изменит изначальную цель налогового контроля трансфертного ценообразования, а, наоборот, позволит приблизиться к ней, обогатить и унифицировать практику применения методов трансфертного ценообразования на глобальном уровне.

Для того чтобы удостовериться в таком подходе в каждом конкретном случае, при решении вопроса о возможности применения рекомендаций Руководства представляется необходимым выявить экономическую цель того или иного правила НК РФ и рекомендации Руководства и проследить их общность. Причем, на наш взгляд, следует признать позицию Минфина России о применимости Руководства только к трансграничным сделкам, нарушающим принцип равенства налогообложения, - вышеописанный подход должен в равной мере применяться ко всем налогоплательщикам и ко всем сделкам.

Таким образом, представляется возможным использование рекомендаций Руководства в России в части применения методов трансфертного ценообразования как продолжающих, конкретизирующих, развивающих, восполняющих пробелы в российском регулировании, в случае если логика и цель налогового контроля трансфертного ценообразования в Руководстве и в НК РФ совпадают. В отсутствие прямых указаний НК РФ без возможности учета рекомендаций Руководства компании и налоговые органы окажутся лишенными оснований доказывать экономически логичный подход, ведущий к наиболее достоверным выводам.

Рассмотрим противоположный пример. При разрешении спора о завышенных расходах $3 \mathrm{AO}$ «МУМТ» доводы заявителя о распределении расходов на российских участников группы в соответствии с принципами ОЭСР по трансфертному ценообразованию были отклонены судом апелляционной инстанции как не соответствую- щие положениям налогового законодательства, которое в рассматриваемый период исключало возможность применения Руководства, не предусматривало принятия расходов на основании соглашений о внутригрупповом распределении расходов (в соответствии с Руководством соглашение о распределении затрат (cost contribution arrangement, cost sharing arrangement) представляет собой соглашение между предприятиями о разделении расходов и рисков, связанных с разработкой, производством или приобретением активов, услуг или прав либо об определении природы и степени интересов каждого из участников в результатах деятельности по разработке, производству или приобретению активов, услуг или прав. В соответствии с данным соглашением доля участия каждого партнера в общих расходах будет пропорциональна его доле в планируемых доходах или иных результатах. Как указано в подп. 8.3 п. В.1 раздела VIII Руководства, каждый участник будет вправе использовать полученные результаты отдельно как их собственник, а не как лицензиат, т.е. без уплаты роялти или иной платы в пользу какой-либо из сторон) и не допускало возможности передачи расходов между самостоятельными юридическими лицами» [17].

Таким образом, российская судебная практика обоснованно отказывается от применения Руководства напрямую, в отсутствие соответствующих норм в российской правовой системе.

Данный подход представляется обоснованным, поскольку Руководство, имея рекомендательный характер, очевидно, не может применяться к процедурным правилам налогового контроля трансфертного ценообразования, т.е. области дискреции законодателя в выборе административно-правовых средств обеспечения налогового регулирования (например, в части определения перечня контролируемых сделок, порядка проведения проверок полноты исчисления и уплаты налогов в связи с совершением сделок между взаимозависимыми лицами, соглашений о ценообразовании). Иной подход нарушал бы экономическую безопасность и суверенитет Российской Федерации. 


\section{Налоги и налогообложение 8(146) • 2016}

\section{Библиография}

1. ОЭСР в системе международных организаций. Цели и институциональное устройство // http:// www.oecdru.org/oecd_sys.html (дата обращения: 23.12.2015).

2. Руководство ОЭСР по трансфертному ценообразованию для транснациональных корпораций и налоговых органов. 16 августа 2010 // http://www.oecd-ilibrary.org/taxation/oecd-transfer-pricingguidelines-for-multinational-enterprises-and-tax-administrations-2010_tpg-2010-еn (дата обращения: 23.12.2015).

3. Мамбеталиева А.Н. Контроль за трансфертным ценообразованием в государствах — членах ЕврАзЭС (правовой обзор) // Финансовое право. М.: Издательская группа «Юрист», 2010. №6. С. 34.

4. План действий ОЭСР «О размывании налогооблагаемой базы и выводе прибыли из-под налогообложения» // http://www.oecd.org/tax/action-plan-on-base-erosion-and-profit-shifting-9789264202719en.htm (дата обращения: 23.12.2015).

5. Основные направления налоговой политики Российской Федерации на 2013 год и на плановый период 2014 и 2015 годов // http://www.consultant.ru/document/cons_doc_LAW_129118/ (дата обращения: 23.12.2015).

6. Постановление ФАС Северо-Западного округа от 19.04.2011 по делу №A56-94331/2009 // http:// kad.arbitr.ru/Card/dc94ac63-cdaa-4e48-bc86-3c2147ac5167 (дата обращения: 26.07.2016).

7. Постановление Девятого арбитражного апелляционного суда от 09.08.2010 по делу №A40131465/09-142-981 // http://kad.arbitr.ru/Card/7a484022-f5e9-4038-8545-229b55338а81 (дата обращения: 26.07.2016).

8. Постановление Девятого арбитражного апелляционного суда от 25.02.2015 по делу №A4028065/13 // http://kad.arbitr.ru/Card/98f7dffc-69f9-413a-9cd9-62d0ad17dbef (дата обращения: 26.07.2016).

9. Письма Минфина России от 18.03.2015 №03-01-18/14680 // https://normativ.kontur.ru/document ?moduleId=1\&documentId=250026 (дата обращения: 31.07.2016), от 18.06.2013 №03-01-18/22698 // https://normativ.kontur.ru/document?moduleId=1\&documentId=222026 (дата обращения: 31.07.2016).

10. Письмо Минфина России от 16.08.2013 №03-01-18/33520 // https://normativ.kontur.ru/document? moduleId=1\&documentId=217676 (дата обращения: 31.07.2016).

11. Налоговый кодекс Российской Федерации (часть первая) от 31.07.1998 №146-Ф3 (ред. от 13.07.2015) // http://www.consultant.ru/document/cons_doc_LAW_19671 (дата обращения: 26.07.2016).

12. Овсянников С.В. Формы и пределы взаимодействия гражданского и налогового права // Вестник ВАС РФ. М.: Издательская группа «ЗАКОН», 2009. №1. С. 88

13. Зарипов В.М. Налоговая льгота: понятие и основные элементы. В сб.: Налоговое право в решениях Конституционного Суда Российской Федерации 2011 года. М.: Норма, 2012. С. 68

14. Хаванова И.А. Экономическое основание налога как принцип “надзаконного” значения // Налоги. М.: Издательская группа «Юрист», 2013. N 5. С. 42-45.

15. Ровинский Е.А. Основные вопросы теории советского права. М.: Госюриздат, 1960. С.134

16. Калинин С.И. Сопоставимость условий сделок и функциональный анализ в НК РФ и руководстве ОЭСР о трансфертном ценообразовании // Закон. М.: Издательская группа «ЗАКОН». 2013. №1. C. 77-80.

17. Определения ВАС РФ от 15.07.2013 №BAC-7048/13 //http://kad.arbitr.ru/Card/3d142210-88b5-4659a45b-71b63d579bc3 (дата обращения: 26.07.2016), от 22.05.2014 №BAC-6044/14 // http://kad.arbitr. ru/Card/ec52e997-7dd4-4c91-beca-e9d14191e2f7 (дата обращения: 26.07.2016). 


\section{References (transliterated)}

1. OESR v sisteme mezhdunarodnykh organizatsii. Tseli i institutsional'noe ustroistvo // http://www. oecdru.org/oecd_sys.html (data obrashcheniya: 23.12.2015).

2. Rukovodstvo OESR po transfertnomu tsenoobrazovaniyu dlya transnatsional'nykh korporatsii i nalogovykh organov. 16 avgusta 2010 // http://www.oecd-ilibrary.org/taxation/oecd-transferpricing-guidelines-for-multinational-enterprises-and-tax-administrations-2010_tpg-2010-en (data obrashcheniya: 23.12.2015).

3. Mambetalieva A.N. Kontrol' za transfertnym tsenoobrazovaniem v gosudarstvakh - chlenakh EvrAzES (pravovoi obzor) // Finansovoe pravo. M.: Izdatel’skaya gruppa «Yurist», 2010. №6. S. 34.

4. Plan deistvii OESR «O razmyvanii nalogooblagaemoi bazy i vyvode pribyli iz-pod nalogooblozheniya» // http://www.oecd.org/tax/action-plan-on-base-erosion-and-profit-shifting-9789264202719-en.htm (data obrashcheniya: 23.12.2015).

5. Osnovnye napravleniya nalogovoi politiki Rossiiskoi Federatsii na 2013 god i na planovyi period 2014 i 2015 godov // http://www.consultant.ru/document/cons_doc_LAW_129118/ (data obrashcheniya: 23.12.2015).

6. Postanovlenie FAS Severo-Zapadnogo okruga ot 19.04.2011 po delu №A56-94331/2009 // http://kad. arbitr.ru/Card/dc94ac63-cdaa-4e48-bc86-3c2147ac5167 (data obrashcheniya: 26.07.2016).

7. Postanovlenie Devyatogo arbitrazhnogo apellyatsionnogo suda ot 09.08 .2010 po delu №A40-131465/09142-981 // http://kad.arbitr.ru/Card/7a484022-f5e9-4038-8545-229b55338a81 (data obrashcheniya: 26.07.2016).

8. Postanovlenie Devyatogo arbitrazhnogo apellyatsionnogo suda ot 25.02 .2015 po delu №A40-28065/13 // http://kad.arbitr.ru/Card/98f7dffc-69f9-413a-9cd9-62d0ad17dbef (data obrashcheniya: 26.07.2016).

9. Pis'ma Minfina Rossii ot 18.03.2015 №03-01-18/14680 // https://normativ.kontur.ru/document?moduleI d=1\&documentId=250026 (data obrashcheniya: 31.07.2016), ot 18.06.2013 №03-01-18/22698 // https:// normativ.kontur.ru/document?moduleId=1\&documentId=222026 (data obrashcheniya: 31.07 .2016 ).

10. Pis'mo Minfina Rossii ot 16.08.2013 №03-01-18/33520 // https://normativ.kontur.ru/document?modu leId=1\&documentId=217676 (data obrashcheniya: 31.07.2016).

11. Nalogovyi kodeks Rossiiskoi Federatsii (chast' pervaya) ot 31.07.1998 №146-FZ (red. ot 13.07.2015) // http://www.consultant.ru/document/cons_doc_LAW_19671 (data obrashcheniya: 26.07.2016).

12. Ovsyannikov S.V. Formy i predely vzaimodeistviya grazhdanskogo i nalogovogo prava // Vestnik VAS RF. M.: Izdatel'skaya gruppa «ZAKON», 2009. №1. S. 88

13. Zaripov V.M. Nalogovaya l'gota: ponyatie i osnovnye elementy. V sb.: Nalogovoe pravo v resheniyakh Konstitutsionnogo Suda Rossiiskoi Federatsii 2011 goda. M.: Norma, 2012. S. 68

14. Khavanova I.A. Ekonomicheskoe osnovanie naloga kak printsip "nadzakonnogo" znacheniya // Nalogi. M.: Izdatel'skaya gruppa «Yurist», 2013. N 5. S. 42-45.

15. Rovinskii E.A. Osnovnye voprosy teorii sovetskogo prava. M.: Gosyurizdat, 1960. C.134

16. Kalinin S.I. Sopostavimost' uslovii sdelok i funktsional'nyi analiz v NK RF i rukovodstve OESR o transfertnom tsenoobrazovanii // Zakon. M.: Izdatel'skaya gruppa «ZAKON». 2013. №1. S. 77-80.

17. Opredeleniya VAS RF ot 15.07.2013 №VAS-7048/13 //http://kad.arbitr.ru/Card/3d142210-88b5-4659a45b-71b63d579bc3 (data obrashcheniya: 26.07.2016), ot 22.05.2014 №VAS-6044/14 // http://kad.arbitr. ru/Card/ec52e997-7dd4-4c91-beca-e9d14191e2f7 (data obrashcheniya: 26.07.2016). 